\title{
Microwave-assisted low temperature synthesis of sodium zirconium phosphate (NZP) and the leachability of some selected fission products incorporated in its structure - A case study of leachability of cesium
}

\author{
A H NAIK ${ }^{1}$, S B DEB ${ }^{2}$, A B CHALKE ${ }^{3}$, M K SAXENA ${ }^{2}$, K L RAMAKUMAR $^{2}$, \\ $\mathrm{V}_{\text {VENUGOPAL }}^{4}$ and S R DHARWADKAR ${ }^{5, *}$ \\ ${ }^{1}$ The Institute of Science, 15, Madam Cama Road, Mumbai 400032 \\ ${ }^{2}$ Trace Element Analysis Section, BARC, Mumbai 400085 \\ ${ }^{3}$ Material Science Department, TIFR, Homi Bhabha Road, Colaba, Mumbai 400005 \\ ${ }^{4}$ Radiochemistry and Isotope Group, BARC, Mumbai 400085 \\ ${ }^{5}$ Department of Chemistry, University of Mumbai, Kalina, Mumbai 400098 \\ e-mail: srdharwadkar@hotmail.com
}

\begin{abstract}
Microwave-assisted procedure for low temperature solid state synthesis of sodium zirconium phosphate (NZP), a material with the potential for immobilization and disposal of high level nuclear waste, was developed. Three selected fission products, namely, Cesium, Strontium and Tellurium were introduced (substituted) in the NZP matrix during its synthesis at $450^{\circ} \mathrm{C}$. Leaching studies were carried out on the fission product substituted NZP sintered at $1000^{\circ} \mathrm{C}$, in pure de-ionized water and $80 \%$ saturated brine solution at the ambient temperatures of $30^{\circ} \mathrm{C}$ and $90^{\circ} \mathrm{C}$ for four weeks. The major part of leaching in all the cases was observed in the first week. The extent of leaching after four weeks was found not exceeded from 12 to $15 \%$ of the elements substituted in NZP, which later became negligibly small. The effect of temperature and the nature of leachant on the leaching rate did not indicate any systematic trend. The EDX analysis of the surfaces of the leached NZP pellets showed that the leaching of the dopants is limited mainly to the surface region of the sintered pellets.
\end{abstract}

Keywords. Microwave aided synthesis; SEM; EDX; XRD; HLW immobilization; leaching.

\section{Introduction}

Immobilization and safe disposal of highly radioactive waste produced during irradiation of nuclear fuel is a matter of great concern in nuclear power generation. Much of this waste comprising of several radioactive elements remains hazardous for thousands of years, leaving a deadly radioactive legacy to future generations. The most important mandate of the nuclear establishments is therefore, to immobilize this waste and isolate it from the public.

\subsection{Immobilization of radioactivity}

1.1a Fixation of radioactivity in glass: Borosilicate glass ${ }^{1-3}$ is currently used for the fixation of high level nuclear waste (HLW) in several nuclear power generating plants around the world. The procedure involves the concentration of the nitrate waste solution obtained after reprocessing of the spent fuel and

*For correspondence adding it to the mixture of glass forming components, comprising of boric acid, sodium carbonate and silica. This results in the formation of the slurry from which water and other volatile components are removed by slow heating and the resulting oxides from the nitrates are incorporated in the glass matrix by heating the charge to the pouring temperature of glass which could be as high as $1150^{\circ} \mathrm{C}$. During this process, oxides of several elements such as those of $\mathrm{Cs}, \mathrm{Te}, \mathrm{Ru}$, etc. vaporize and get deposited in the ducts and pipelines connected to the processing plant making this area inaccessible for work to the technicians, due to high radioactivity. It is therefore necessary to devise a process by which these elements could be fixed into the solid matrix at temperatures low enough, where the vaporization of these oxides is not significant.

The other disadvantage of fixing the radioactivity in glass is mainly due to its thermodynamically meta-stable nature. The solidified radioactive glass contained in special steel canisters located in the repositories can spontaneously de-vitrify and the 
heat produced due to this transformation could breach the canister and expose its radioactive contents to the environment.

1.1b Potential of ceramic matrices for immobilization of nuclear waste: Several attempts have been made to develop suitable thermodynamically stable solid ceramic matrices with the potential to fix the radio nucleides. ${ }^{4-10}$ Ringwood and co-workers ${ }^{4}$ synthesized several perovskite and pyrochlore structure based ceramic phases which could be used for fixation of number of radioactive elements. But each of these phases could be used for immobilization of only specific elements. They considered the use of the mixture of several phases for the fixation of several nucleides together, and termed this assemblage as SYNROC. Similar attempts were also made by Roy and co-workers. ${ }^{6-10}$ The solid state synthesis routes adopted by these investigators for the preparation of these compounds, particularly in the case of SYNROC, used sophisticated technique such as hot iso-static pressing (HIP) involving the use of very high temperatures and high pressures and were not cost effective.

The development of SYNROC was followed by several attempts to prepare thermodynamically stable ceramics which would accommodate large number of fission products in a single ceramic matrix without major structural alteration. Scheetz and co-workers ${ }^{7}$ in their recent review presented the potential of sodium zirconium phosphate (NZP) as the most suitable candidate for the replacement of glass for fixing the high level nuclear waste. They observed that almost all the fission products could be accommodated in NZP owing to its peculiar structure. Few experiments on the fixation and leaching of HLW performed on NZP were promising, ${ }^{7,11}$ but the potential of this material as a substitute for glass however, is yet to be established firmly. The details of the structure and the potential sites for substitution of different fission products based on the ionic size of the substituents and the structure of NZP are presented in several publications. ${ }^{11-14}$

\section{Experimental}

\subsection{The methods reported for the preparation of NZP}

Three different methods have been used by the earlier investigators for the preparation of the com- pounds in NZP family. These include: (i) Sol-gel method $^{15-20}$; (ii) Solid state $\operatorname{method}^{21-26}$ and (iii) Hydrothermal reactions. ${ }^{27,28}$ Almost all the methods reported for the synthesis of NZP are time consuming, need speciality chemicals like alkoxides ${ }^{19,20}$ and temperatures in excess of $800^{\circ} \mathrm{C}$. Breval et $\mathrm{al}^{13}$ synthesized low-thermal-expansion materials in NZP family by the combustion reaction method using low cost chemicals including urea as a fuel and $\mathrm{NH}_{4} \mathrm{NO}_{3}$ as an oxidizer, zirconium oxynitrate, and ammonium dihydrogen phosphate. Govindan Kutty ${ }^{29}$ prepared NZP by heating the mixture of Zirconyl chloride or nitrate, sodium carbonate and ammonium dihydrogen phosphate at temperature as low as $600^{\circ} \mathrm{C}$ in conventional resistance furnace. Vaidynathan and $\mathrm{RaO}^{30}$ prepared NZP by heating the mixture of $\mathrm{NaH}_{2} \mathrm{PO}_{4} \cdot 2 \mathrm{H}_{2} \mathrm{O},\left(\mathrm{NH}_{4}\right)_{2} \cdot \mathrm{HPO}_{4}$ and $\mathrm{ZrO}_{2}$ in stoichiometric proportion in microwave oven. The reaction was represented as

$$
\begin{array}{r}
\mathrm{NaH}_{2} \mathrm{PO}_{4} \cdot 2 \mathrm{H}_{2} \mathrm{O}+2\left(\mathrm{NH}_{4}\right)_{2} \mathrm{HPO}_{4}+2 \mathrm{ZrO}_{2} \\
\mathrm{NaZr}_{2} \mathrm{P}_{3} \mathrm{O}_{12}+6 \mathrm{H}_{2} \mathrm{O}+\mathrm{NH}_{3} \uparrow .
\end{array}
$$

Vaidynathan and $\mathrm{RaO}^{30}$ performed elaborate experiments to prove that among the reaction components used, only $\mathrm{NaH}_{2} \mathrm{PO}_{4} \cdot 2 \mathrm{H}_{2} \mathrm{O}$ remained microwaveactive after dehydration and mainly contributed to microwave heating of the reaction mixture The method proposed by NIST ${ }^{31}$ involved heating of the mixture of $\mathrm{ZrO}_{2}, \mathrm{NaHPO}_{4}$ and $\left(\mathrm{NH}_{4}\right)_{2} \mathrm{HPO}_{4}$ in resistance furnace above $1200^{\circ} \mathrm{C}$ for $12 \mathrm{~h}$ with repeated grinding.

\subsection{The basis for the procedure adopted in the present work}

2.2a Thermal analysis of the reaction mixture: Among the three methods outlined above the method proposed by Kutty ${ }^{29}$ was adopted in the present investigation, with the difference that the conventional resistance heating of the mixture was changed to microwave heating. The choice was based on the fact that ammonia released in the reaction could be oxidized by nitrate providing the local exothermicity, in addition to the heating provided by the interaction of the reaction components with the microwave radiation. The reaction involved heating of the mixture of $\mathrm{Na}_{2} \mathrm{CO}_{3}, \mathrm{ZrO}\left(\mathrm{NO}_{3}\right)_{2} \cdot 5 \mathrm{H}_{2} \mathrm{O}$ and $\left(\mathrm{NH}_{4}\right) \mathrm{H}_{2} \mathrm{PO}_{4}$ in the ratio $1: 2: 3$ at $600{ }^{\circ} \mathrm{C}$. The overall reaction could be represented by the equation 


$$
\begin{aligned}
\mathrm{Na}_{2} \mathrm{CO}_{3} & +4 \mathrm{ZrO}\left(\mathrm{NO}_{3}\right)_{2} \cdot 5 \mathrm{H}_{2} \mathrm{O}+6 \mathrm{NH}_{4} \mathrm{H}_{2} \mathrm{PO}_{4} \\
& +17 / 2 \mathrm{O}_{2} \rightarrow 2 \mathrm{NaZr}_{2} \mathrm{P}_{3} \mathrm{O}_{12}+38 \mathrm{H}_{2} \mathrm{O} \\
& +14 \mathrm{NO}_{2} \uparrow+\mathrm{CO}_{2} \uparrow .
\end{aligned}
$$

The choice of selection of reaction temperature was based on the information provided by thermogravimetry, and differential scanning calorimeter. ${ }^{32}$ The simultaneous TG-DSC plot recorded employing the SETARAM simultaneously recording TG-DSC unit, for the reaction mixture in argon is shown in figure 1. It is clear from the TG curve that the total mass loss of the mixture resulting due to dehydration, denitration, deammoniation and decarbonation is virtually complete by $500^{\circ} \mathrm{C}$, which is expected to be completed at much lower temperature if the mixture is heated isothermally. DSC curve however, shows some interesting features. The first endothermic peak $\left(120^{\circ} \mathrm{C}\right)$ which could mainly be attributed to dehydration, was followed by a prominent exothermic peak $\left(300^{\circ} \mathrm{C}\right)$ which could involve simultaneous denitration, deammoniation and decarbonation. The exothermicity of this peak could be understood in terms of the oxidation of the evolved ammonia in the mixture by nitrate. Though the decomposition reaction is complete by around $500^{\circ} \mathrm{C}$, another conspicuous broad exothermic peak was observed around this temperature. This broad exothermic peak could be understood only if the product formed after the completion of the reaction around $500^{\circ} \mathrm{C}$ is amorphous. The thermal data in figure 1 provided the guideline for optimizing the temperature of heat treatment of the reaction mixture to obtain pure NZP.

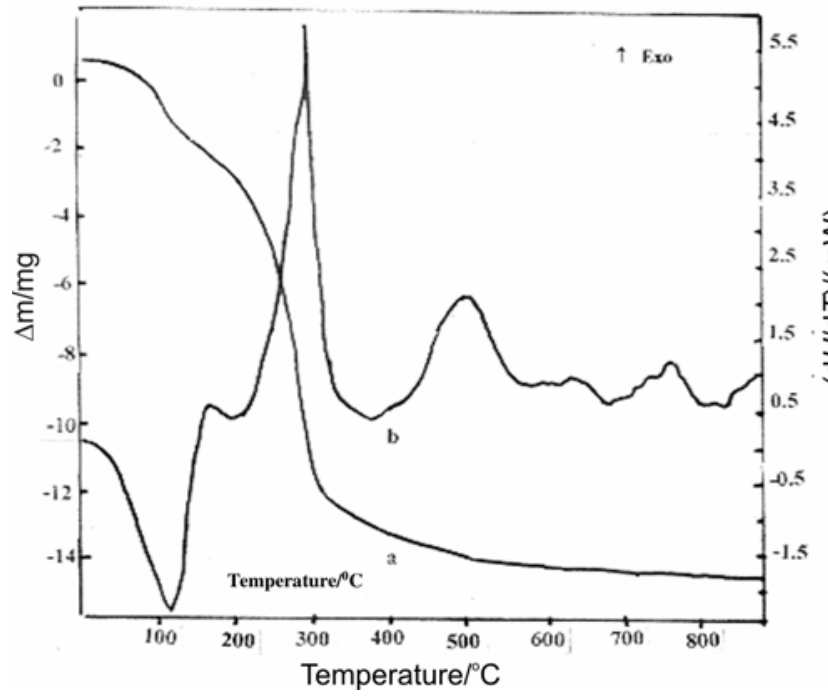

Figure 1. Simultaneous thermogravimetric and differential scanning calorimetry plot for the reaction mixture.
The exothermicity observed in the reaction mixture (DSC peak around $300^{\circ} \mathrm{C}$ ) during the decomposition facilitated the formation of NZP at low temperatures as in the case of self propagating high temperature reactions. ${ }^{33-36}$ Adopting microwave heating was expected to further decrease the reaction temperature, ${ }^{37}$ which, in fact, was observed in the recent work of Ganesh and co-investigators. ${ }^{38}$

\section{2b Characterization of NZP by $X$-ray diffraction:}

$\mathrm{X}$-ray diffraction pattern (figure $2 \mathrm{a}$ ) of the product obtained by heating the reaction mixture at $450^{\circ} \mathrm{C}$ in conventional resistance heated furnace for $1 \mathrm{~h}$ indicated that the product was indeed partially crystalline. The same mixture heated in microwave oven at the same temperature $\left(450^{\circ} \mathrm{C}\right)$ for the same duration yielded highly crystalline NZP (figure $2 b$ ) nearly as crystalline as the product obtained by heating the reaction mixture at $650^{\circ} \mathrm{C}$ (figure $2 \mathrm{c}$ ) for the same time interval. The highly crystalline nature of NZP obtained from the reaction mixture heated in the resistance furnace at $650^{\circ} \mathrm{C}$ in air, confirmed that the broad exothermic peak around $500^{\circ} \mathrm{C}$ (figure 1) was indeed due to crystallization of the partially amorphous NZP formed below $500^{\circ} \mathrm{C}$.

\section{1c The procedure adopted for the preparation of} pure and fission elements doped NZP: In the procedure developed, the stoichiometric $(1: 2: 3)$ mixture of sodium carbonate, zirconyl nitrate pentahydrate and ammonium dihydrogen phosphate was thoroughly ground in agate mortar and homogenized in acetone. The mixture frothed and became sticky during grinding, probably due to evolution of carbon dioxide by the reaction of sodium carbonate with highly acidic zirconyl nitrate hydrate. The product obtained was ball milled in presence of acetone and dried in air oven at $90^{\circ} \mathrm{C}$ till free flowing powder was obtained which was then heated in microwave heating system (MHS), at $450^{\circ} \mathrm{C}$. The fission products $(\mathrm{Cs}, \mathrm{Sr}, \mathrm{Te})$ doped NZP was obtained by adding the appropriate salts or oxides of these elements to the reaction mixture prior to heating.

The quantities of original components in the reaction mixture were appropriately adjusted to accommodate 1 to $2 \mathrm{a} / 0$ of the substituted elements. XRD patters of pure as well as doped NZP samples were found to be identical and yielded the value for the volume of the unit cell within $1 \%$ of that reported by Sizova $^{39}$ for pure NZP. The substitution of selected fission product elements in the parent NZP matrix 

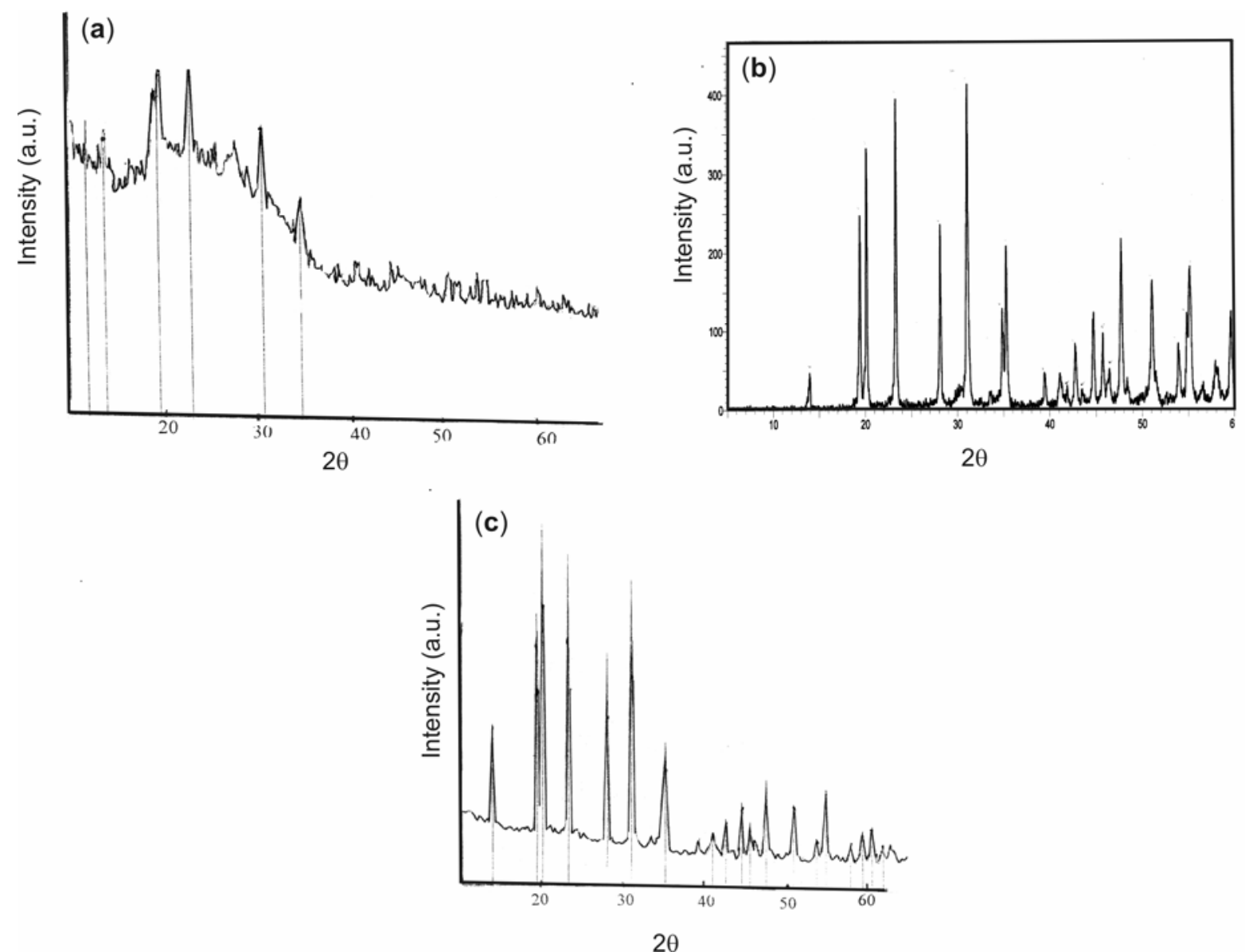

Figure 2. (a) XRD pattern of the product obtained by heating mixture of $\mathrm{Na}_{2} \mathrm{CO}_{3}, \mathrm{ZrO}\left(\mathrm{NO}_{3}\right)_{2} ; 5 \mathrm{H}_{2} \mathrm{O}$ and $\left(\mathrm{NH}_{4}\right) \mathrm{H}_{2} \mathrm{PO}_{4}$ in resistance heated furnace at $450^{\circ} \mathrm{C}$ for $1 \mathrm{~h}$. (b) XRD pattern of the product obtained by heating mixture of $\mathrm{Na}_{2} \mathrm{CO}_{3}, \mathrm{ZrO}\left(\mathrm{NO}_{3}\right)_{2} ; 5 \mathrm{H}_{2} \mathrm{O}$ and $\left(\mathrm{NH}_{4}\right) \mathrm{H}_{2} \mathrm{PO}_{4}$ in microwave oven at $450^{\circ} \mathrm{C}$ for $1 \mathrm{~h}$. (c) XRD pattern of the product obtained by heating mixture of $\mathrm{Na}_{2} \mathrm{CO}_{3}, \mathrm{ZrO}\left(\mathrm{NO}_{3}\right)_{2} ; 5 \mathrm{H}_{2} \mathrm{O}$ and $\left(\mathrm{NH}_{4}\right) \mathrm{H}_{2} \mathrm{PO}_{4}$ in resistance heated furnace at $650^{\circ} \mathrm{C}$ for $1 \mathrm{~h}$.

was confirmed by EDX analysis (table 1). The total concentration of the dopants in the NZP matrix was limited to $2 \%$. The elements were doped either singly, in pairs or triads.

The concentration of the dopants introduced in NZP determined by EDX where based on limited data obtained by scanning the sample at few points on the sample surface and may not be representative of the whole bulk. More accurate results were therefore obtained by chemical analysis which involve dissolution of the samples in $\mathrm{HCl}$, $\mathrm{HF}$ mixture in the ratio $85: 15$ at $160^{\circ} \mathrm{C}$ employing microwave heating. Good agreement was seen in the concentration values of the dopants added to the reaction mixture and those derived from chemical analysis (table 2) indicating that the dopants added in the mixture were retained in the product obtained at $450^{\circ} \mathrm{C}$ quantitatively. The concentration of the dopant elements in the solution prepared from doped NZP was determined by flame photometry and ICP-MS. ${ }^{40}$

\section{1d Densification of NZP and determination of} the concentration of dopants in the sintered compacts: NZP prepared by the above method had to be sintered to high density to minimize the leaching of the doped elements. $2 \mathrm{~mm}$ thick, $12 \mathrm{~mm}$ diameter green NZP pellets obtained by compacting the powder applying the uniaxial pressure of 2.8 tonnes/ sq. inch were analysed dilatometically in order to optimize the temperature of sintering. The sintering temperature should not be too high in order to prevent the loss of the dopants from NZP. The shrinkage data for the pellets doped with different selected elements are presented in figure 3 . It can be concluded from the figure that NZP sinters rapidly above $850^{\circ} \mathrm{C}$. Optimum temperature for sintering 
Table 1. Comparison of the amount of dopant added in the reaction mixture with that estimated in the reaction product by EDX.

\begin{tabular}{lcc}
\hline Combination & $\begin{array}{c}\text { Amount of Cs added } \\
\text { (atom percentage) }\end{array}$ & $\begin{array}{c}\text { Amount of Cs estimated } \\
\text { by EDX analysis } \\
\text { (atom percentage) }\end{array}$ \\
\hline $\mathrm{Cs}$ & $2 \cdot 0$ & $2 \cdot 87$ \\
$\mathrm{Sr}-\mathrm{Cs}$ & $1 \cdot 0$ & $1 \cdot 12$ \\
$\mathrm{Sr}-\mathrm{Cs}-\mathrm{Te}$ & $1 \cdot 0$ & 1.23 \\
\hline
\end{tabular}

Table 2. Amount of the elements in the doped NZP prepared at $450^{\circ} \mathrm{C}$.

\begin{tabular}{lcccc}
\hline Combination & Element & $\begin{array}{c}\text { Amount } \\
\text { added* }(\mathrm{mg})\end{array}$ & $\begin{array}{c}\text { Amount estimated by } \\
\text { MW dissolution }(\mathrm{mg})\end{array}$ & $\begin{array}{c}\text { Amount estimated by } \\
\text { flame photometry (mg) }\end{array}$ \\
\hline $\mathrm{Cs}$ & $\mathrm{Cs}$ & $12 \cdot 19$ & $12 \cdot 25$ & 11.83 \\
$\mathrm{Sr}-\mathrm{Cs}$ & $\mathrm{Sr}$ & $4 \cdot 02$ & 4.50 & $4 \cdot 21$ \\
& $\mathrm{Cs}$ & $6 \cdot 10$ & $6 \cdot 11$ & $6 \cdot 02$ \\
$\mathrm{Sr}-\mathrm{Cs}-\mathrm{Te}$ & $\mathrm{Sr}$ & $4 \cdot 02$ & $4 \cdot 47$ & $4 \cdot 15$ \\
& $\mathrm{Cs}$ & $6 \cdot 10$ & $6 \cdot 10$ & $6 \cdot 23$ \\
& $\mathrm{Te}$ & $5 \cdot 88$ & 4.96 & - \\
\hline
\end{tabular}

*Amount of substituent in $100 \mathrm{mg}$ of the doped NZP

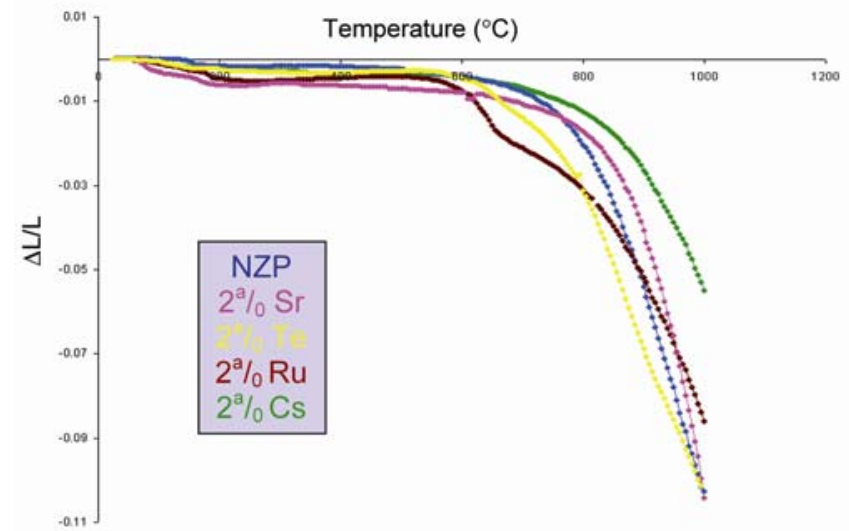

Figure 3. The shrinkage curves recorded for pure and doped samples.

was fixed at $1000^{\circ} \mathrm{C}$ where the rate of sintering was fairly rapid. The pellets heated at this temperature for three hours yielded NZP with densities ranging between 85 and $92 \%$ of the theoretical value. The values of the concentration of the dopants in the sintered compacts determined by chemical analysis are listed in table 3 which indicate small but significant loss of the dopant during the sintering process. It is reported that NZP does not sinter significantly above $1000^{\circ} \mathrm{C}^{41}$ Increasing the temperature of sintering above $1000^{\circ} \mathrm{C}$ would therefore, result only in additional loss of the dopants from NZP.

\section{Leaching studies on fission product doped NZP}

The most important part of this study was to investigate the leaching behaviour of the dopants immobilized in the NZP matrix and to assess the extent to which these elements would find their way in the environment by the interaction with ground waters under accidental conditions. In the leaching experiments, the sintered pellets weighing between 400 and $500 \mathrm{mg}$, containing the dopant was leached in 20 to $25 \mathrm{ml}(\mathrm{V} / \mathrm{SA}=10)$ of the leachant liquid (deionized water or saturated brine solution) at room temperature and at $90^{\circ} \mathrm{C}$. The value of volume to surface area ratio (V/SA) was maintained at 10 as required by the procedure recommended by $\mathrm{MCC} .{ }^{42}$ The concentration of the elements released in the leachants were estimated after 7, 14, 21 and 28 days. The leachant in the container was replaced by a fresh lot after each time interval. The concentration of elements in the leachant was estimated by ICPMS after suitable dilution. The rate of leaching was calculated in $\mathrm{gm} / \mathrm{m}^{2} /$ day as per the procedure $\mathrm{MCC}^{42}$.

The leaching of dense fission product doped NZP was carried out in pure de-ionized water and $80 \%$ saturated brine solution at ambient room temperature and $90^{\circ} \mathrm{C}$ respectively. The studies were carried out on singly as well as multiply doped NZP pellets. 
Table 3. Amount of the elements in NZP matrix before and after sintering.

\begin{tabular}{lccc}
\hline Mode of doping & Element & $\begin{array}{c}\text { Amount estimated } \\
\text { at } 450^{\circ} \mathrm{C}(\mathrm{mg})\end{array}$ & $\begin{array}{c}\text { Amount estimated } \\
\text { at } 1000^{\circ} \mathrm{C}(\mathrm{mg})\end{array}$ \\
\hline $\mathrm{Cs}$ & $\mathrm{Cs}$ & $12 \cdot 25$ & $10 \cdot 15$ \\
$\mathrm{Sr}-\mathrm{Cs}$ & $\mathrm{Sr}$ & $4 \cdot 50$ & $4 \cdot 46$ \\
& $\mathrm{Cs}$ & $6 \cdot 11$ & $6 \cdot 09$ \\
$\mathrm{Sr}-\mathrm{Cs}-\mathrm{Te}$ & $\mathrm{Sr}$ & $4 \cdot 47$ & $5 \cdot 2$ \\
& $\mathrm{Cs}$ & $6 \cdot 10$ & $6 \cdot 10$ \\
& $\mathrm{Te}$ & 4.96 & 4.96 \\
\hline
\end{tabular}

Table 4. Leaching of Cs in deionized water at RT.

\begin{tabular}{cccc}
\hline & & \multicolumn{2}{c}{ Amount of Cs leached $\left(\mathrm{gm} / \mathrm{m}^{2} /\right.$ day $)$} \\
\cline { 3 - 4 } Days & Cs-NZP & Sr-Cs-NZP & Sr-Cs-Te NZP \\
\hline 7 & 1.2913 & 0.0533 & 0.8290 \\
14 & 0.1286 & 0.0157 & 0.0319 \\
21 & 0.0377 & 0.0059 & 0.0160 \\
28 & 0.0020 & 0.0047 & 0.0060 \\
\hline
\end{tabular}

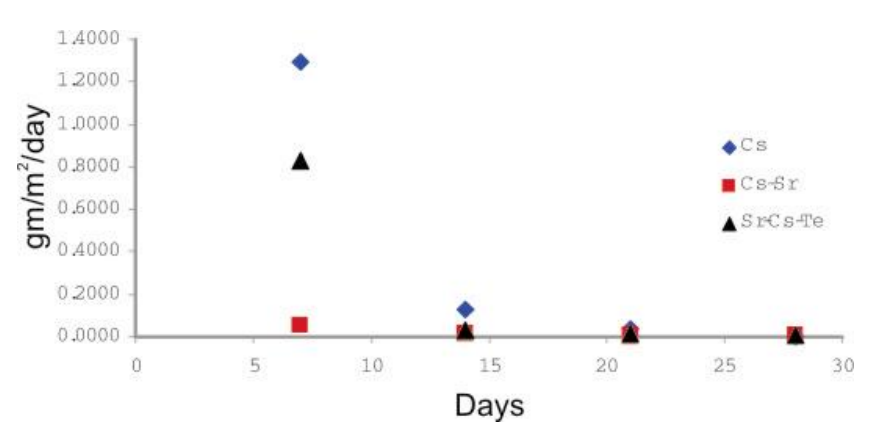

Figure 4. Leaching of Cs in deionized water at RT.

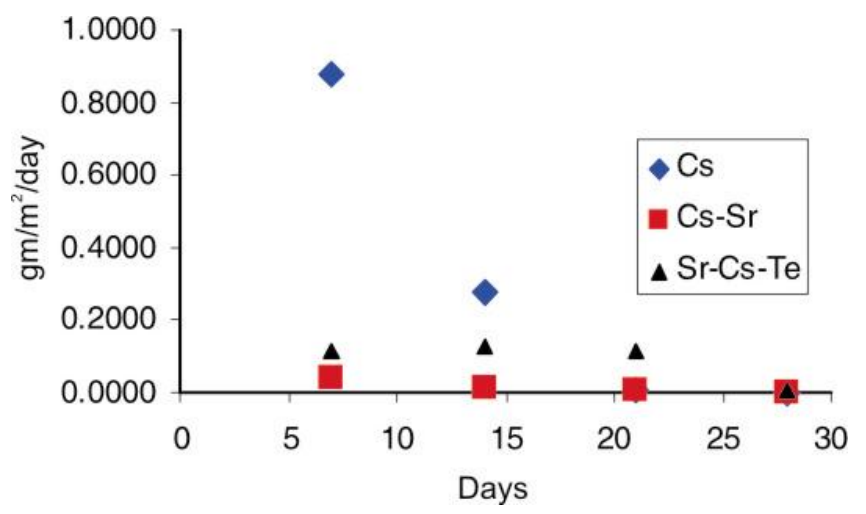

Figure 5. Leaching of $\mathrm{Cs}$ in deionized water at $90^{\circ} \mathrm{C}$.

Results are however presented for only few combinations including $\mathrm{Cs}, \mathrm{Cs}-\mathrm{Sr}$ and $\mathrm{Cs}-\mathrm{Sr}-\mathrm{Te}$. Some data was available in the literature in the case of $\mathrm{Cs}$

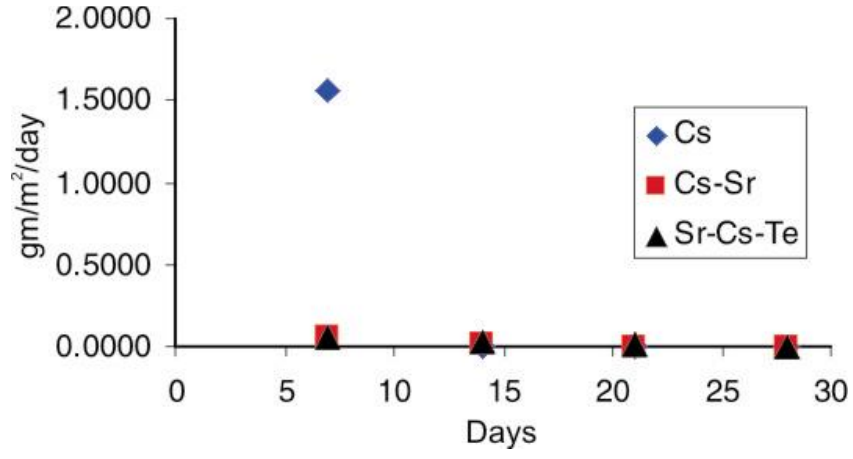

Figure 6. Leaching of $\mathrm{Cs}$ in $80 \%$ saturated brine solution at RT.

and $\mathrm{Cs}-\mathrm{Sr}$ doped samples for comparison. ${ }^{7,11}$ Each element in these combinations was substituted to the extent of $2 \%$ when singly doped and $1 \%$ each when more then one element were substituted in the NZP matrix. Among the doped NZP samples, those doped with $\mathrm{Cs}$ and $\mathrm{Sr}$ and $\mathrm{Cs}, \mathrm{Sr}$ and $\mathrm{Te}$ simultaneously were found to retain much more amount of $\mathrm{Cs}$ in the sintered pellets (table 3 ). It was therefore, decided to study the leachability of $\mathrm{Cs}$ from these samples and compare the results with those obtained on singly $\mathrm{Cs}$ substituted NZP sample.

The results obtained for leaching of $\mathrm{Cs}$ in the combination involving $\mathrm{Cs}-\mathrm{Sr}$ and $\mathrm{Cs}-\mathrm{Sr}-\mathrm{Te}$ in pure deionized water and $80 \%$ brine solution at room temperature and $90^{\circ} \mathrm{C}$ are presented in tables 4 to 7 
Table 5. Leaching of $\mathrm{Cs}$ in deionized water at $90^{\circ} \mathrm{C}$.

\begin{tabular}{cccc}
\hline & & \multicolumn{2}{c}{ Amount of Cs leached $\left(\mathrm{gm} / \mathrm{m}^{2} / \mathrm{day}\right)$} \\
\cline { 3 - 4 } Days & Cs-NZP & Sr-Cs-NZP & Sr-Cs-Te NZP \\
\hline 7 & 0.8816 & 0.0406 & 0.1128 \\
14 & 0.2802 & 0.0128 & 0.1305 \\
21 & 0.0071 & 0.0096 & 0.1124 \\
28 & 0.0029 & 0.0032 & 0.0057 \\
\hline
\end{tabular}

Table 6. Leaching of Cs in $80 \%$ brine water at RT.

\begin{tabular}{cccc}
\hline & & \multicolumn{2}{c}{ Amount of Cs leached $\left(\mathrm{gm} / \mathrm{m}^{2} /\right.$ day $)$} \\
\cline { 3 - 4 } Days & Cs-NZP & Sr-Cs-NZP & Sr-Cs-Te NZP \\
\hline 7 & 1.5654 & 0.0554 & 0.0628 \\
14 & 0.0052 & 0.0141 & $0 \cdot 0242$ \\
21 & 0.0000 & 0.0052 & $0 \cdot 0098$ \\
28 & 0.0000 & 0.0048 & 0.0039 \\
\hline
\end{tabular}

Table 7. Leaching of Cs in $80 \%$ brine water at $90^{\circ} \mathrm{C}$.

\begin{tabular}{lccc}
\hline & & \multicolumn{2}{c}{ Amount of Cs leached $\left(\mathrm{gm} / \mathrm{m}^{2} /\right.$ day $)$} \\
\cline { 3 - 4 } Days & Cs-NZP & Sr-Cs-NZP & Sr-Cs-Te NZP \\
\hline 7 & 0.9870 & 0.0534 & $0 \cdot 1170$ \\
14 & 0.0289 & 0.0139 & 0.0920 \\
21 & 0.0129 & 0.0051 & 0.0707 \\
28 & 0.0012 & 0.0052 & 0.0411 \\
\hline
\end{tabular}

Table 8. The pellet leached at $90^{\circ} \mathrm{C}$ in deionized water.

\begin{tabular}{lcccc}
\hline Mode of doping & Element & $\begin{array}{c}\text { Amount estimated } \\
\text { at } 450^{\circ} \mathrm{C}(\mathrm{mg})\end{array}$ & $\begin{array}{c}\text { Amount estimated in the } \\
\text { pellet sintered at } 1000^{\circ} \mathrm{C}(\mathrm{mg}) \\
\text { (before leaching) }\end{array}$ & $\begin{array}{c}\text { Amount estimated }(\mathrm{mg}) \text { in the } \\
\text { pellet sintered at } 1000^{\circ} \mathrm{C} \\
\text { (after leaching) }\end{array}$ \\
\hline $\mathrm{Cs}$ & $\mathrm{Cs}$ & 12.25 & $10 \cdot 15$ & 9.72 \\
$\mathrm{Sr}-\mathrm{Cs}$ & $\mathrm{Sr}$ & 4.50 & 4.46 & 4.21 \\
& $\mathrm{Cs}$ & $6 \cdot 11$ & 6.09 & 5.90 \\
$\mathrm{Sr}-\mathrm{Cs}-\mathrm{Te}$ & $\mathrm{Sr}$ & 4.47 & 5.20 & 4.9 \\
& $\mathrm{Cs}$ & $6 \cdot 10$ & $6 \cdot 10$ & 5.90 \\
& $\mathrm{Te}$ & 5.88 & 4.96 & 4.86 \\
\hline
\end{tabular}

and plotted in figures 4 to 7 . These results indicate that the leaching of $\mathrm{Cs}$ from $\mathrm{Cs}-\mathrm{Sr}$ and $\mathrm{Cs}-\mathrm{Sr}-\mathrm{Te}$ combinations is much less compared to that from NZP containing Cs alone and the total amount of the dopant element leached after four weeks in none of the cases exceeded 12 to $15 \%$ of the amount originally contained in the sintered pellets. The values of concentration of the dopants in NZP determined before and after four weeks of leaching are listed in table 8 .

\section{Surface analysis of the doped NZP pellets before and after leaching}

\subsection{EDX analysis}

The results of elemental analysis by EDX of the surfaces and the bulk of $\mathrm{Cs}-\mathrm{Sr}$ and $\mathrm{Cs}-\mathrm{Sr}-\mathrm{Te}$ doped NZP pellet before and after leaching for four weeks are presented in tables 9-14. The leaching of Cs-Sr, $\mathrm{Cs}-\mathrm{Sr}-\mathrm{Te}$ containing pellet was done in deionized 
water and in brine solution at RT and $90^{\circ} \mathrm{C}$ respectively. The EDX patterns for the surfaces of unleached $\mathrm{Cs}-\mathrm{Sr}$ substituted NZP and that leached deionized water at $90^{\circ} \mathrm{C}$ are shown in figures 8 and 9. The similar results for surfaces of $\mathrm{Cs}-\mathrm{Sr}-\mathrm{Te}$

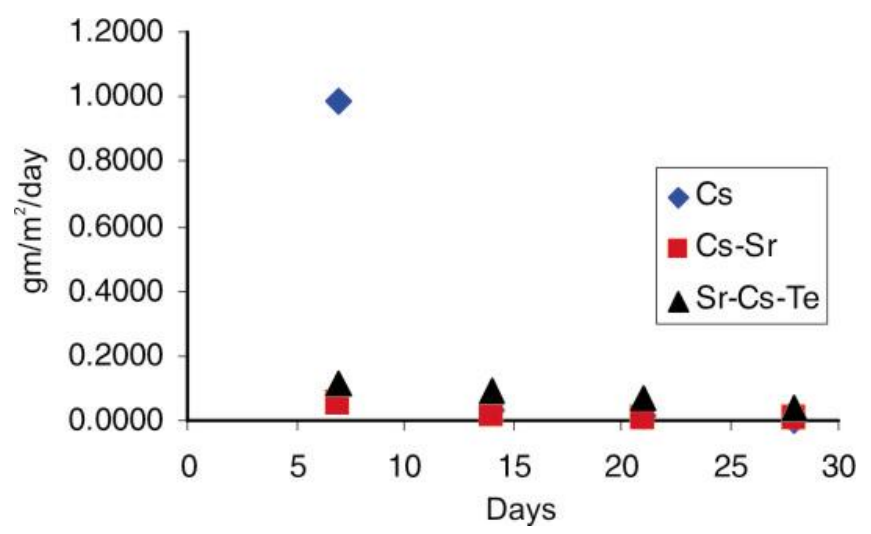

Figure 7. Leaching of $\mathrm{Cs}$ in $80 \%$ saturated brine solution at $90^{\circ} \mathrm{C}$.

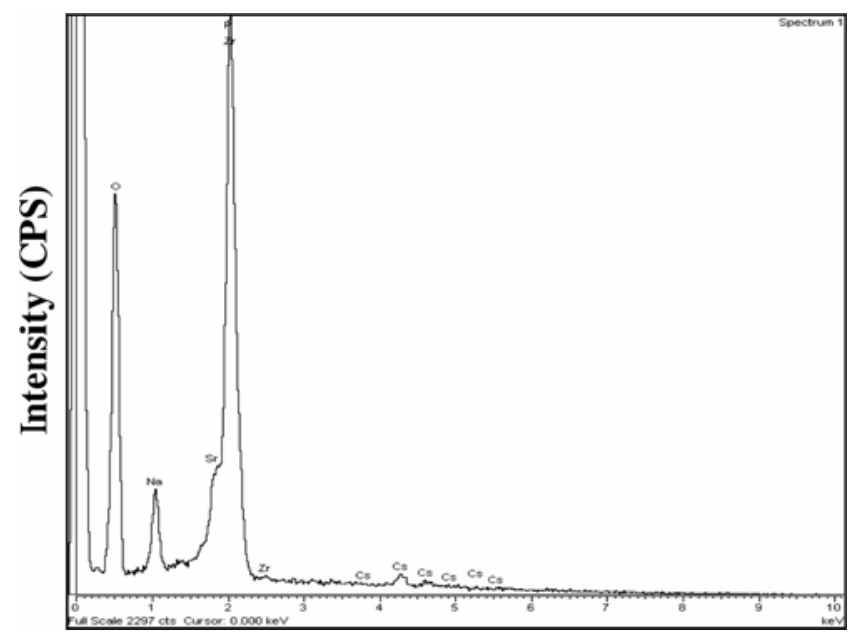

Figure 8. EDX data of unleached $\mathrm{Sr}-\mathrm{Cs}$ NZP.

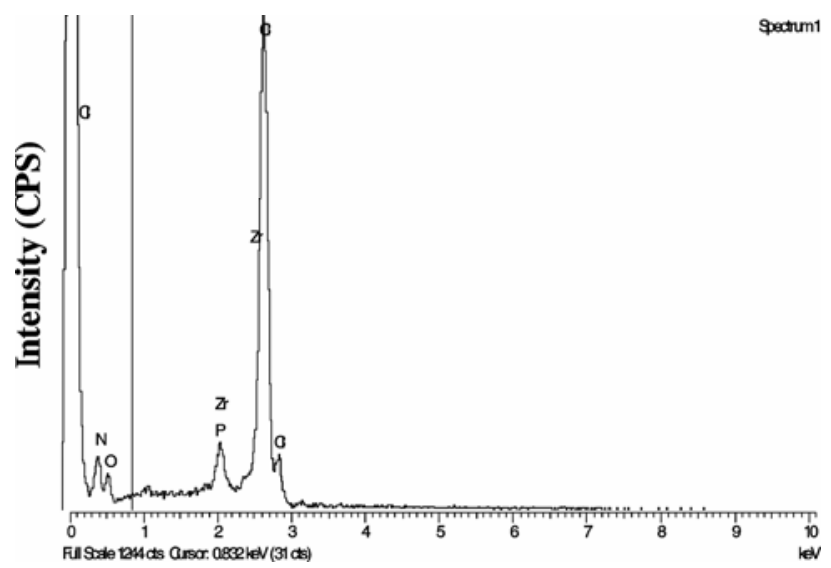

Figure 9. EDX data of $\mathrm{Sr}-\mathrm{Cs}$ NZP on surface of leached pellet. doped pellet were obtained after leaching the pellet at $90^{\circ} \mathrm{C}$ in more chemically hostile environment containing $80 \%$ saturated brine solution. The surface of $\mathrm{Cs}-\mathrm{Sr}$ doped pellet after leaching was virtually

Table 9. EDX data of unleached Sr-Cs NZP.

\begin{tabular}{lcc}
\hline Element & Weight (\%) & Atomic (\%) \\
\hline O K & 31.90 & 62.97 \\
Na K & 3.22 & 4.43 \\
P K & 16.04 & 16.35 \\
Sr L & 5.30 & 1.91 \\
Zr L & 36.78 & 12.73 \\
Cs L & 6.76 & 1.61 \\
Total & 100.00 & - \\
\hline
\end{tabular}

Table 10. EDX data of $\mathrm{Sr}-\mathrm{Cs}$ NZP on surface of leached pellet.

\begin{tabular}{lcc}
\hline Element & Weight $(\%)$ & Atomic $(\%)$ \\
\hline N K & $26 \cdot 55$ & $46 \cdot 18$ \\
O K & $6 \cdot 61$ & $10 \cdot 07$ \\
P K & $1 \cdot 82$ & 1.43 \\
Cl K & 59.40 & $40 \cdot 82$ \\
Zr L & $5 \cdot 61$ & 1.50 \\
Total & $100 \cdot 00$ & - \\
\hline
\end{tabular}

Table 11. Sr-Cs NZP at Center of leached pellet.

\begin{tabular}{lcc}
\hline Element & Weight (\%) & Atomic (\%) \\
\hline O K & 29.03 & 62.17 \\
Na K & 3.95 & 5.88 \\
P K & 21.45 & 23.73 \\
Cs L & 2.68 & 0.69 \\
Pt M & 32.89 & 7.53 \\
Sr & 10.80 & 1.60 \\
Total & 100.00 & - \\
\hline
\end{tabular}

Table 12. EDX data of unleached $\mathrm{Sr}-\mathrm{Cs}-\mathrm{Te}$ NZP.

\begin{tabular}{lcc}
\hline Element & Weight (\%) & Atomic (\%) \\
\hline Na K & $9 \cdot 86$ & $20 \cdot 32$ \\
P K & 32.52 & $49 \cdot 77$ \\
Sr L & 4.75 & 2.57 \\
Zr L & $52 \cdot 00$ & 27.02 \\
Te L & $0 \cdot 87$ & 1.96 \\
Cs L & $7 \cdot 11$ & 1.23 \\
Total & $100 \cdot 00$ & - \\
\hline
\end{tabular}


devoid of Cs (table 10, figure 9). However, in the case of $\mathrm{Cs}-\mathrm{Sr}-\mathrm{Te}$ doped pellet the presence of considerable amount of $\mathrm{Cs}$ was observed on the leached

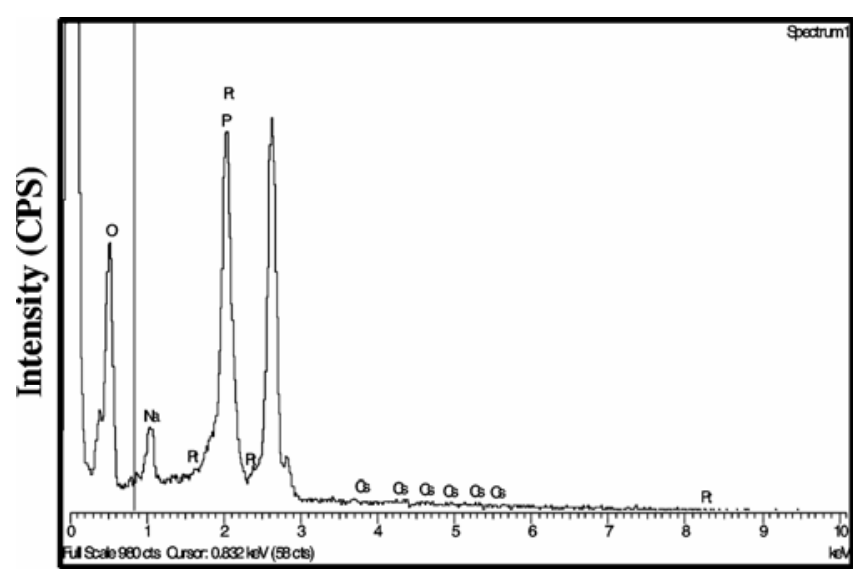

Figure 10. EDX data of $\mathrm{Sr}-\mathrm{Cs} \mathrm{NZP}$ at Center of leached pellet.

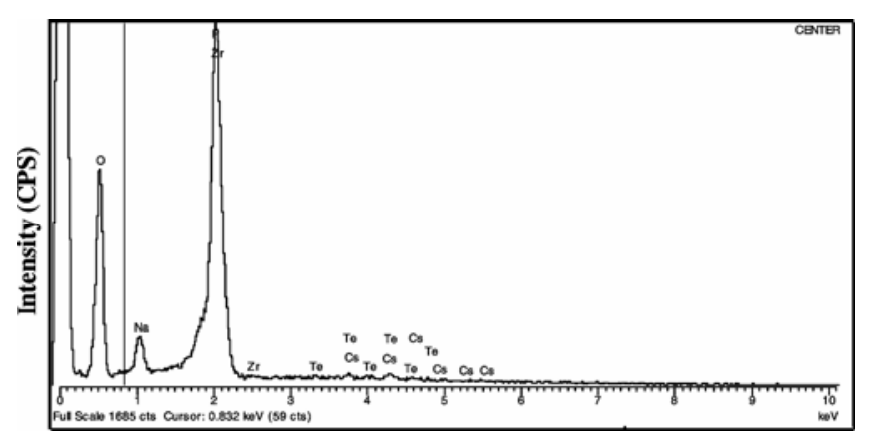

Figure 11. EDX data of $\mathrm{Sr}-\mathrm{Cs}-\mathrm{Te} \mathrm{NZP}$ at Center of leached pellet.

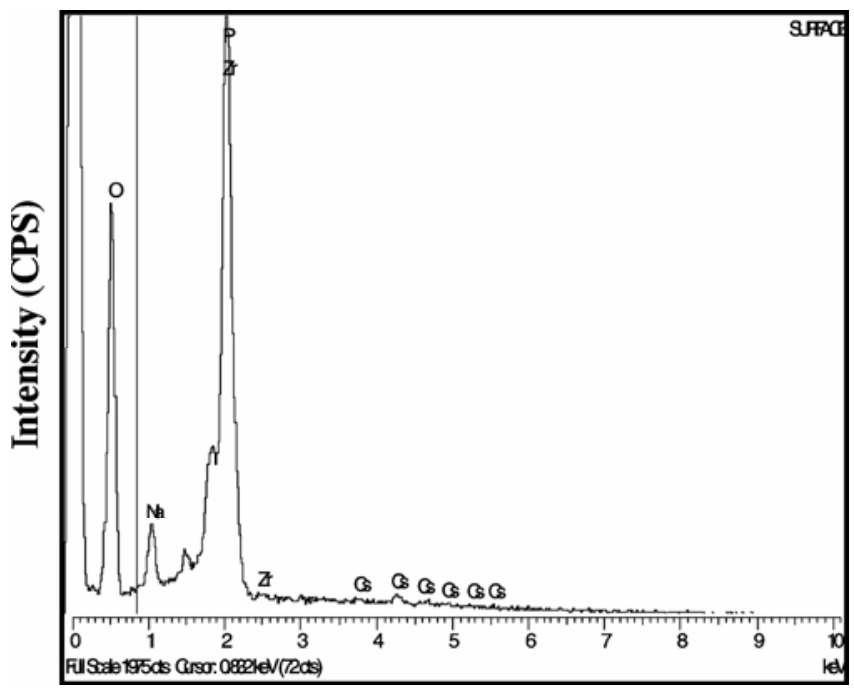

Figure 12. EDX data of $\mathrm{Sr}-\mathrm{Cs}-\mathrm{Te}$ NZP on surface of leached pellet. surface (table 14, figure 12). This is contrary to the observation in table 8 in which the amount of Cs leached in pure deionized water from $\mathrm{Cs}-\mathrm{Sr}-\mathrm{Te}$ containing NZP after four weeks of leaching is much higher than that from $\mathrm{Cs}-\mathrm{Sr}$ containing NZP. This observation suggests that the presence of sodium in the leachant could possibly suppress the dissolution of $\mathrm{Cs}$ from $\mathrm{Cs}-\mathrm{Sr}-\mathrm{Te}$ doped NZP. The analysis of the dopants in the center of the section obtained by cutting it perpendicular to the diameter revealed that while there is significant depletion of $\mathrm{Cs}$ in the case of $\mathrm{Cs}-\mathrm{Sr}$ (table 11, figure 10) doped pellet, there is no sizeable variation in the concentration of $\mathrm{Cs}$ from surface to center in the case of $\mathrm{Cs}-\mathrm{Sr}-\mathrm{Te}$ (table 13, figure 11) containing NZP pellet after leaching indicating the suppression of leaching of $\mathrm{Cs}$ from the pellet. The concentration of $\mathrm{Cs}$ in the centre of the CS-Sr doped pellet determined by EDX is however much lower than that expected on the basis of the total Cs estimated in the leached sample (table 3). This could be due to very few data points recorded by EDX for the estimation of Cs. More studies are needed to examine the influence of the presence of $\mathrm{NaCl}$ in the leachant on the leaching behaviour of doped elements in the NZP matrix.

\section{Conclusions}

Pure and fission products ( $\mathrm{Cs}, \mathrm{Sr}, \mathrm{Te}$ and $\mathrm{Ru}$ ) substituted NZP could be prepared in highly crystallined

Table 13. EDX data of $\mathrm{Sr}-\mathrm{Cs}-\mathrm{Te} \mathrm{NZP}$ at center of leached pellet.

\begin{tabular}{lcc}
\hline Element & Weight\% & Atomic\% \\
\hline O K & $30 \cdot 90$ & 62.23 \\
Na K & $2 \cdot 59$ & 3.63 \\
P K & $16 \cdot 72$ & 17.39 \\
Zr L & 41.90 & 14.80 \\
Te L & 2.93 & $0 \cdot 74$ \\
Cs L & 4.96 & $1 \cdot 20$ \\
Totals & $100 \cdot 00$ & - \\
\hline
\end{tabular}

Table 14. EDX data of $\mathrm{Sr}-\mathrm{Cs}-\mathrm{Te}$ NZP on surface of leached pellet.

\begin{tabular}{lcc}
\hline Element & Weight\% & Atomic\% \\
\hline O K & $34 \cdot 75$ & 65.46 \\
Na K & 2.69 & 3.53 \\
P K & 16.97 & 16.52 \\
Zr L & $40 \cdot 08$ & 13.24 \\
Cs L & 5.51 & 1.25 \\
Totals & $100 \cdot 00$ & - \\
\hline
\end{tabular}


Table 15. Studies on 1a/o Cs-1a/o Sr NZP.

\begin{tabular}{|c|c|c|c|c|}
\hline \multirow[b]{2}{*}{ Element } & \multicolumn{2}{|c|}{ 1a/o Cs-1a/o Sr-NZP (our work) } & \multicolumn{2}{|c|}{ 1a/o Cs-1 ${ }^{\mathrm{a}} / \mathrm{o} \mathrm{Sr}-\mathrm{NZP}(\text { Zyrynov})^{11}$} \\
\hline & Days & Leaching rate $\left(\mathrm{gm} / \mathrm{m}^{2} /\right.$ day $)$ & Days & Leaching rate $\left(\mathrm{gm} / \mathrm{m}^{2} /\right.$ day $)$ \\
\hline Cs & $\begin{array}{r}7 \\
28\end{array}$ & $\begin{array}{l}0 \cdot 04 \\
0 \cdot 003\end{array}$ & $\begin{array}{r}7 \\
28\end{array}$ & $\begin{array}{l}0 \cdot 02 \\
0 \cdot 002\end{array}$ \\
\hline Sr* & $\begin{array}{r}7 \\
28\end{array}$ & $\begin{array}{l}0 \cdot 015 \\
0 \cdot 003\end{array}$ & $\begin{array}{r}7 \\
28\end{array}$ & $\begin{array}{l}0 \cdot 01 \\
0 \cdot 003\end{array}$ \\
\hline
\end{tabular}

*Results to be published separately

Table 16. Comparison of our data with that reported in the literature CsZP.

\begin{tabular}{|c|c|c|c|c|}
\hline \multirow[b]{2}{*}{ No. of days } & \multicolumn{2}{|c|}{ 2a/o Cs-NZP (our work) } & \multicolumn{2}{|c|}{ Cs ZP (Scheetz et. $\left.a l^{7}\right)$} \\
\hline & $\begin{array}{c}\text { Temperature } \\
\left({ }^{\circ} \mathrm{C}\right)\end{array}$ & $\begin{array}{l}\text { Leaching rate } \\
\left(\mathrm{gm} / \mathrm{cm}^{2} / \text { day }\right)\end{array}$ & $\begin{array}{c}\text { Temperature } \\
\left({ }^{\circ} \mathrm{C}\right)\end{array}$ & $\begin{array}{l}\text { Leaching rate } \\
\left(\mathrm{gm} / \mathrm{cm}^{2} / \text { day }\right)\end{array}$ \\
\hline 14 & RT & $1.3 \times 10^{-5}$ & - & - \\
\hline 14 & 90 & $2.8 \times 10^{-5}$ & 110 & $2 \times 10^{-5}$ \\
\hline
\end{tabular}

form at temperature as low as $450^{\circ} \mathrm{C}$, at which the volatility of most of the fission products is insignificant, by proper choice of the reactants employing microwave heating technique. The quantitative retention of all the fission products added to the reaction mixture in the resulting NZP could be confirmed by chemical analysis.

Pure and fission product doped NZP could be sintered to nearly 85 to $92 \%$ of theoretical density by heating at $1000^{\circ} \mathrm{C}$ for $3 \mathrm{~h}$. The loss of the dopants due to heat treatment during sintering was limited to 12 to $15 \%$ of the amount contained in doped NZP prepared at $450^{\circ} \mathrm{C}$.

Leaching of $\mathrm{Cs}$ from the sintered pellets of doped $\mathrm{NZP}$ containing $\mathrm{Cs}, \mathrm{Cs}-\mathrm{Sr}$ and $\mathrm{Cs}-\mathrm{Sr}-\mathrm{Te}$ indicated maximum leaching in the case where only $\mathrm{Cs}$ was doped in NZP. The extent of leaching was much less for other two combinations. The concentration of the dopants determined in the leachant and the doped pellets after leaching confirmed that almost $90 \%$ of the elements doped in NZP matrix were retained in most of the cases even after leaching for more than 28 days. Changing of leachant from pure de-ionised water to $80 \%$ saturated brine solution in the case of $\mathrm{CS}-\mathrm{Sr}-\mathrm{Te}$ combination resulted in the retention of maximum $\mathrm{Cs}$ in the doped NZP.

The temperature had small but significant effect on the leaching rate. The average leaching rates of Cs decreased with increasing temperature in the case of pure $\mathrm{Cs}$ and $\mathrm{Cs}-\mathrm{Sr}$ doped NZP.

The extent of leaching and the leaching rate of the doped fission products from NZP was also influ- enced by changing the leaching medium from deionized water to $80 \%$ saturated brine solution. In case of $\mathrm{Cs}$, there is increase of initial leaching rate; however, the leaching rate after two weeks attains nearly the same value in all the Cs containing samples.

The results obtained in this investigation certainly demonstrate the potential of NZP as a candidate for the fixation of high level nuclear waste. However, the present data cannot be compared with that of leaching from glass matrix due to unavailability of such information from the literature. Most of the studies involving leaching of glass, monitor the loss of sodium from the matrix during leaching. The superiority of NZP for immobilization of HLW over glass however can only be established, when the leaching of the elements selected in the present work is studied from the glass matrix in the same concentration range under the identical set of experimental conditions. The present data obtained for the leaching of fission products embedded in the NZP matrix indicate that the leaching rates of these elements from this matrix is at least two orders magnitude lower than that of sodium from borosilicate based glass. $^{43}$

There are very limited data in the literature to compare the leachability of fission products from NZP in the present work. The only information available in the literature on this topic ${ }^{7,11}$ is summarized in tables 15 and 16.

Luo et $a l^{44}$ presented the leaching rate data on 1 atom percent $\mathrm{Cs}$ and $\mathrm{Sr}$ doped SYNROC at $110^{\circ} \mathrm{C}$ in pure water (table 17). It is observed that the leaching 
Table 17. Comparison with SYNROC (after 7 days of leaching).

\begin{tabular}{lccccc}
\hline & \multicolumn{2}{c}{$1 \mathrm{a} /{ }_{0} \mathrm{Cs}-1 \mathrm{a} / \mathrm{oSr}-\mathrm{NZP}$} & & \multicolumn{2}{c}{ SYNROC } \\
\cline { 2 - 3 } \cline { 5 - 6 } Element & Temperature & $\begin{array}{c}\text { Leaching rate } \\
\left(\mathrm{gm} / \mathrm{m}^{2} / \text { day }\right)\end{array}$ & & Temperature & $\begin{array}{c}\text { Leaching rate } \\
\left(\mathrm{gm} / \mathrm{m}^{2} / \text { day }\right)\end{array}$ \\
\hline $\mathrm{Cs}$ & $90^{\circ} \mathrm{C}$ & $\begin{array}{r}4 \times 10^{-2} \\
\mathrm{Sr}\end{array}$ & & $110^{\circ} \mathrm{C}$ & $5.64 \times 10^{-2}$ \\
\cline { 5 - 6 } & & $1.5 \times 10^{-2}$ & & & $2.83 \times 10^{-2}$ \\
\hline
\end{tabular}

rates of these two elements from SYNROC at $110^{\circ} \mathrm{C}$ are within the same order of magnitude of that of leaching of $\mathrm{Cs}$ from 1 atom percent doped $\mathrm{Cs}-\mathrm{Sr}$ NZP

The most important conclusion from the present work is that in the case of immobilization of high level nuclear waste on NZP and its disposal, the leaching of the waste partially from this matrix would provide the barrier for further leaching. The extent to which the dopants are leached do not exceed about $15 \%$ of the quantity incorporated in NZP. In the event of exposure of such partially doped material to ground water there will be much less risk of the radioactivity entering the environment. Further, there will be much less leaching of $\mathrm{Cs}$ in geological locations containing rock salt in the event of accidental exposure of the material to the underground hot water sources. Much data however need to be collected to justify the claim based on few observations reported in this investigation.

More data on leaching of $\mathrm{Sr}$ and Te under the set of conditions identical to those in the present work will be published separately.

\section{Acknowledgements}

The authors are thankful to the Board of Research in Nuclear Sciences (BRNS) of the Department of Atomic Energy (DAE) for the financial support for this work under contract No.2000/37/19/BRNS/1959/ dtd 09-02-02. Dr Amol H Naik gratefully acknowledges the Fellowship offered to him by DAE to carry out this work.

\section{References}

1. Ojovam M I and Karlina O K 1992 Radiochim. Acta. 3497

2. Roth G and Weisenburger S 2000 Nucl. Eng. Design 202197

3. Plodinec M J 2000 Glass Technol. 41186

4. Ringwood A E, Kesson S E, Ware N G, Hibberson W and Major A 1979 Nature 278219
5. MacCarthy G J, White W B and Pfoertsch D E 1978 Mater. Res. Bull. 131239

6. Roy R., Vance E R and Alamo J 1982 Mater. Res. Bull. 17585

7. Scheetz B E, Agrawal D K, Breval E and Roy R 1994 Waste Manage. 14489

8. Vance E R and Ahmad F L 1983 Mater. Res. Soc. Symp. Proc. 15105

9. Yang L J, Komarneni S and Roy R 1984 Mater. Res. Soc. Symp. Proc. 26567

10. Komarneni S and Roy R 1983 Mater. Res. Soc. Symp. Proc. 15177

11. Zyryanov V N and Vance E R 1996 Mater. Res. Soc. Symp. Proc. (Boston, MA) December 1-6

12. Nakayama S and Itoh K 2003 J. Nucl. Sci. Tech. 40 631

13. Breval E, MacKinstry H A and Agrawal D K $2000 \mathrm{~J}$. Mater. Sci. 353359

14. Agrawal D K 1994 J. Mater. Educ.16 139

15. Alamo J and. Roy R $1948 \mathrm{~J}$. Am. Cer. Soc. C-78-C80

16. Alamo J and Roy R 1986 J. Mater. Sci. 21444

17. Kuriakose A V, Wheat T A, Ahmad A and Pirocco J 1984 J. Am. Cer. Soc. 67179

18. Agrawal D K and Adair J H 1990 J. Am. Cer. Soc. 73 2153

19. Yoldas B E and Lloyd I K 1983 Mater. Res. Bull. 18 1171

20. Perthuis H and Colomban P H 1984 Mater. Res. Bull. 19621

21. Clearfield A., Jirustithipong P, Cotman R N and Pack S P 1980 Mater. Res. Bull. 151603

22. Clearfield A, Roberts B D and Subramanian M A 1983 Mater. Res. Bull. 19219

23. Clearfield A, Subramanian M A, Wang W and Jerus P 1983 Solid State Ionic 9895

24. Kinoshita M and Inoue M 1980 Chem. Soc. Japan 8 1219

25. Miller G R, McEntire B J, Handnagy T D, Rasmussen J R and Gordon R S 1997 In Fast transport in solid (eds) Vashishta, Mundy and Shenoy (Elsevier North Holland), p. 83

26. Quon D H, Wheat T A and Nesbitt W 1980 Mater. Res. Bull. 151533

27. Komarneni S 1988 Int. J. High Tech. Ceram. 431

28. Yamanaka S, Yoshioka K and Hattori M 1990 Solid State Ionics $\mathbf{4 0} 43$

29. Govindan Kutty K V, Direct solid state synthesis of sodium zirconium phosphate at low temperature. IGCAR, Kalpakkam, India (private communication) 
30. Vaidyanathan B and Rao K J 1997 J. Solid State Chem. 132349

31. Natl. Bur. Stand. (US) 1982 Monogr. 2581

32. Naik A H, Thakkar N V, Singh Mudher K D, Venugopal V and Dharwadkar S R 2004 J. Thermal Anal. \& Calorimetry 8707

33. Vaidhyanathan B, Agrawal D K and Roy R $2000 \mathrm{~J}$. Mater. Res. 15974

34. Peng J H, Binner J and Bradshaw S 2002 Mater. Sci. \& Tech. 181419

35. Marzhanov A G 1993 Int. J. Self-Propag High-Temp Synth. 2113

36. Patil K C 1993 Bull. Mater. Sci. 16533

37. Agrawal D K 1998 Current opinions in solid state and materials science 3480 and references therein

38. Ganesh I, Johnson R, Mahajan Y R, Khan A, Madhavendra S S and Reddy B M 2004 J. Mater. Res. 19 1015
39. Sizova R G, Voronkov A A, Shumayatska NG, Ilukhin V V and Belov N V 1973 Soviet Phys. Dokladi 17718

40. Naik A H 2007 Ph D thesis, Submitted to the Mumbai University

41. Hawkins H 1996 M.S. thesis, Material Science Lab., University of Penn, US

42. International Organization for Standardization, Longterm leaching testing of solidified radioactive waste forms. 1982 International Standard, Ref. No. ISO6961

43. Kaushik C P, Mishra R K, Katarni V G, Kumar Amar, Thorat V, Soudamini N, Ozarde P D and Raj Kanwar, Sengupta P, Kale G B and De P K 2004 Performance evaluation of vitrified waste product based on barium-borosilicate matrix developed for vitrification of sulpahte bearing high level radioactive liquid waste, BARC report no. BARC/2004/ E/19

44. Luo L, Li Tang B and Wang D 1998 Waste Management 1855 